\title{
Expression of TMEM106B, the frontotemporal lobar degeneration-associated protein, in normal and diseased human brain
}

Johanna I Busch 1,4, Maria Martinez-Lage ${ }^{2,5}$, Emily Ashbridge ${ }^{1,4}$, Murray Grossman 1,6, Vivianna M Van Deerlin², Fenghua Hu ${ }^{3,8}$, Virginia MY Lee ${ }^{2,9}$, John Q Trojanowski ${ }^{2,9}$ and Alice S Chen-Plotkin ${ }^{1,4^{*}}$

\begin{abstract}
Background: Frontotemporal lobar degeneration (FTLD) is the second most common cause of dementia in individuals under 65 years old and manifests as alterations in behavior, personality, or language secondary to degeneration of the frontal and/or temporal lobes. FTLD-TDP, the largest neuropathological subset of FTLD, is characterized by hyperphosphorylated, ubiquitinated TAR DNA-binding protein 43 (TDP-43) inclusions. Mutations in progranulin (GRN), a neuroprotective growth factor, are one of the most common Mendelian genetic causes of FTLD-TDP. Moreover, a recent genome-wide association study (GWAS) identified multiple SNPs within the uncharacterized gene TMEM106B that significantly associated with FTLD-TDP, suggesting that TMEM106B genotype confers risk for FTLD-TDP. Indeed, TMEM106B expression levels, which correlate with TMEM106B genotype, may play a role in the pathogenesis of disease.
\end{abstract}

Results: Since little is known about TMEM106B and its expression in human brain, we performed immunohistochemical studies of TMEM106B in postmortem human brain samples from normal individuals, FTLD-TDP individuals with and without GRN mutations, and individuals with other neurodegenerative diseases. We find that TMEM106B protein is cytoplasmically expressed in both histopathologically affected and unaffected areas of the brain by neurons, glia, and endothelial cells/pericytes. Furthermore, we demonstrate that TMEM106B expression may differ among neuronal subtypes. Finally, we show that TMEM106B neuronal expression is significantly more disorganized in FTLD-TDP cases with GRN mutations, compared to normal and disease controls, including FTLD-TDP cases without GRN mutations.

Conclusions: Our data provide an initial neuropathological characterization of the newly discovered FTLD-TDP -associated protein TMEM106B. In addition, we demonstrate that FTLD-TDP cases with GRN mutations exhibit a loss of neuronal TMEM106B subcellular localization, adding to evidence that TMEM106B and progranulin may be pathophysiologically linked in FTLD-TDP.

Keywords: TMEM106B, Frontotemporal lobar degeneration, Frontotemporal dementia, TDP-43, Progranulin, FTLD-TDP

\footnotetext{
* Correspondence: chenplot@mail.med.upenn.edu

${ }^{1}$ Departments of Neurology, Perelman School of Medicine at the University

of Pennsylvania, Philadelphia, PA, USA

${ }^{4}$ Department of Neurology, Perelman School of Medicine, 3610 Hamilton

Walk, 166 Johnson Pavilion, Philadelphia, PA 19104, USA

Full list of author information is available at the end of the article
} 


\section{Background}

Frontotemporal lobar degeneration (FTLD) is a fatal neurodegenerative disease characterized by selective degeneration of the frontal and temporal lobes [1,2]. Functionally, patients often present with alterations in behavior, personality and language, rather than with memory impairment as seen in patients with Alzheimer's disease [3-5]. FTLD is neuropathologically classified into two major subtypes: FTLD-tau and FTLD-TDP $[4,6]$. FTLDtau cases are characterized by abnormal accumulations of the microtubule-associated protein tau in neurons and glia, while FTLD-TDP cases harbor neuronal inclusions of ubiquitinated, hyperphosphorylated TAR DNA-binding protein 43 (TDP-43) $[7,8]$.

FTLD-TDP comprises approximately $50 \%$ of clinical FTLD [9]. Mutations in the progranulin gene (GRN), which codes for a growth factor with neuroprotective effects $[10,11]$ account for $\sim 10 \%$ of FTLD-TDP [12-14]. The majority of these autosomal dominant mutations result in premature termination codons and thus progranulin haploinsufficiency $[14,15]$. In addition, expansions in the C9orf72 gene have recently been shown to be an important Mendelian cause of FTLD-TDP [16,17]. However, the majority of FTLD-TDP cases do not show clear Mendelian patterns of inheritance.

In order to identify additional genetic risk factors, we previously performed a genome-wide association study (GWAS) and identified multiple SNPs within the uncharacterized gene TMEM106B that significantly associated with FTLD-TDP (odds ratio 1.6, $\mathrm{p}=1.08 \times 10^{-11}$ for top SNP rs1990622) [18]. This association has been replicated in a clinically diagnosed cohort of patients [19] and was most recently replicated in a cohort of FTLD-TDP patients carrying GRN mutations [20], although other investigators have not replicated the association [21]. We and others have investigated the physiological [22-24] and pathophysiological [25-28] function of TMEM106B. TMEM106B genetic variants may confer increased disease risk by increasing levels of TMEM106B expression, since mRNA expression levels of TMEM106B are $>2.5$-fold higher in FTLD-TDP cases vs. controls [18], and are particularly increased in FTLD-TDP cases with GRN mutations [24]. Moreover, TMEM106B risk genotypes have been associated with higher levels of TMEM106B expression in lymphoblastoid cell lines [29] and in human brain tissue $[18,24]$, suggesting that the variants found by GWAS tag a cis-acting mechanism for regulating TMEM106B expression. One possible mechanism was recently identified by Nicholson et al. [20], who demonstrated that differential isoforms at the coding SNP rs3173615 (p.T185S), which is in linkage disequilibrium with the GWAS SNP rs1990622, result in different rates of protein degradation. The risk (T185) isoform of TMEM106B is degraded less quickly than the protective
(S185) form of TMEM106B. Together, these data suggest that TMEM106B variants resulting in higher levels of TMEM106B protein may increase disease risk.

Evidence further suggests that TMEM106B risk genotypes/increased TMEM106B expression may modulate disease risk by affecting progranulin pathways. For example, TMEM106B risk genotypes have been associated with decreased plasma progranulin levels [26], and significantly earlier onset of disease in GRN mutation carriers [27]. Moreover, TMEM106B, which localizes to late endosomes / lysosomes in multiple cell lines and in mouse primary cortical and hippocampal neurons [22-24], has been shown to co-localize with progranulin $[20,23,24]$. Intriguingly, expression of TMEM106B as compared to control results in increased intracellular progranulin $[20,23,24]$, and changes progranulin's apparent subcellular compartmentalization as visualized by immunofluorescence microscopy [24].

While studies to date have established TMEM106B as an important risk factor for FTLD-TDP and implicated TMEM106B in progranulin pathways, many basic features of this protein -- including its expression patterns in human brain -- are largely unknown. To further characterize this novel disease-related protein, we investigate here the distribution and appearance of TMEM106B in postmortem human brain samples from normal and disease controls, FTLD-TDP individuals with GRN mutations (GRN (+) FTLD-TDP), and FTLD-TDP individuals without GRN mutations (GRN (-) FTLD-TDP).

\section{Results}

\section{TMEM106B expression by cell type in normal human}

\section{brain tissue}

We began by characterizing TMEM106B expression in normal human brain tissue. As shown in Figure 1, we found that TMEM106B is expressed in neurons, glia, and in cells surrounding blood vessels in frontal and occipital cortical samples from normal controls. Specifically, TMEM106B is a cytoplasmic protein that assumes a polarized, perikaryal distribution in neurons (Figure 1a). Glial cells also demonstrate TMEM106B in an asymmetric, polarized pattern within the cytoplasm (Figure 1b). Finally, occasional robust TMEM106B immunoreactivity was observed peri-vascularly, in endothelial cells or pericytes (Figure 1c). TMEM106B immunoreactivity in neurons and glia was observed throughout all layers of neocortex, with prominent expression in the pyramidal neurons of layers 3-5 (Figure $2 \mathrm{a}$ ).

\section{TMEM106B expression by brain region in normal human brain tissue}

We next evaluated whether TMEM106B expression and appearance varies by brain region. In occipital cortex, a region of the brain relatively spared from TDP-43 


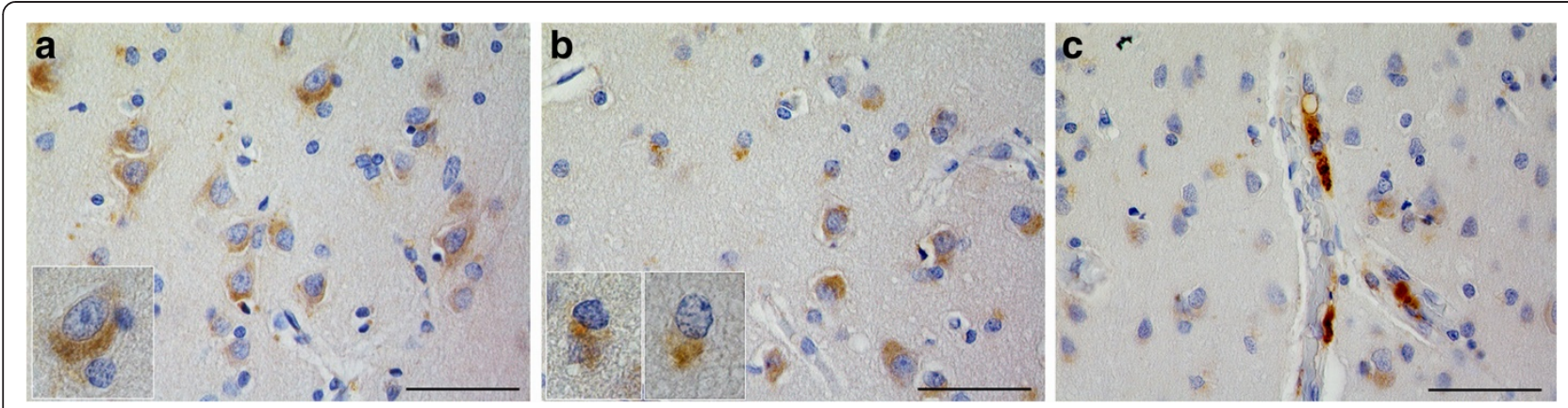

Figure 1 TMEM106B expression in neurons, glial and endothelial cells or pericytes in cortical specimens from normal controls.

TMEM106B is normally cytoplasmically expressed in neurons (a), glia (b), and endothelial cells or pericytes (c). (a) Neuronal staining in cortices from normal human controls demonstrated a perikaryal, polarized cytoplasmic distribution mainly in the cell body and variably extending into processes. (b) Glial distribution of TMEM106B similarly demonstrated an asymmetric cytoplasmic distribution. (c) A subset of endothelial cells or pericytes demonstrated intense cytoplasmic expression of TMEM106B. Sections were stained with the anti-TMEM106B polyclonal antibody N2077 [24]. Scale bar represents 50 um.

pathology, neurons and glia had a similar perikaryal, cytoplasmic pattern of TMEM106B expression when compared to neurons and glia of frontal cortex, a brain region which typically displays a heavy burden of TDP43 pathology (Figure 2b and c) [30].

In the hippocampus, however, whereas TMEM106B expression was clearly seen in the pyramidal neurons of Ammon's horn (Figure 2d), no significant staining of the dentate gyrus was observed (Figure 2e), suggesting neuronal subtype specificity of TMEM106B expression. Lentiform nucleus sections from normal controls showed minimal TMEM106B expression (Figure 2f); additionally, neurons of the nucleus basalis of Meynert had little to no staining (not pictured). In cerebellar sections, Purkinje cells demonstrated little TMEM106B expression (Figure 2g), and neurons of the granular layer did not stain for TMEM106B (Figure 2g). In contrast, neurons of the deep cerebellar nuclei showed diffuse TMEM106B immunoreactivity with varying degrees of granularity (Figure $2 h$ ).

In summary, we observed variability in TMEM106B expression by neuronal subtype. However, TMEM106B expression did not demonstrate obvious differences in neocortical regions vulnerable to neurodegeneration, compared to those relatively resilient to neurodegeneration, in FTLD-TDP.

\section{TMEM106B expression in FTLD-TDP brain}

Given the putative role of TMEM106B in FTLD-TDP, we stained frontal cortex, occipital cortex, cerebellar, hippocampal, and lentiform nucleus sections from individuals with GRN (+) FLTD-TDP, GRN (-) FTLD-TDP, and normal controls. In addition, we included FTLD-tau, and Alzheimer's disease (AD) brain samples as nonFTLD-TDP disease controls.

While FTLD-TDP is characterized by neuronal cytoplasmic inclusions (NCI) and (depending on histological subtype) neuronal intranuclear inclusions (NII) of TDP-
43, these TDP-43-containing pathological inclusions did not contain TMEM106B. Furthermore, TMEM106B did not appear to form pathological inclusions of any type in the eleven FTLD-TDP cases investigated here. Comparing normal and disease-affected specimens, however, we noted greater variability in the appearance of TMEM106B cytoplasmic staining among the disease cases. Specifically, in neurons, cytoplasmic TMEM106B ranged from an organized perikaryal distribution to a disordered phenotype in which TMEM106B was expressed diffusely throughout the cell body and even extended into neuronal processes.

To further characterize these differences, we semiquantitatively rated specimens based on their degree of apparent TMEM106B disorganization and loss of subcellular localization using an ordinal scale ranging from 0 (most polarized/organized) to 3 (most diffuse/disorganized). Specifically, two individuals blinded to disease status rated 29 frontal cortex samples for patterns of TMEM106B staining, as described in Figure 3a (normal controls $\mathrm{n}=7 ; \mathrm{AD} \mathrm{n}=5$; FTLD-tau $\mathrm{n}=6$, GRN (+) FTLD-TDP $\mathrm{n}=6$, GRN (-) FTLD-TDP $\mathrm{n}=5$ ).

Inter-rater reliability was moderately high (weighted kappa $=0.44)$. Moreover, as shown in Figure 3b, GRN (+) FTLD-TDP cases showed the most disorganized patterns of TMEM106B staining, with an average score (2.125) that was significantly greater when compared to all other cases (Mann-Whitney test, $\mathrm{p}=0.005$ ). Moreover, while TMEM106B expression rarely extended into neuronal processes for normal controls, FTLD-tau, AD, or GRN (-) FTLD-TDP cases, in every GRN (+) FTLD-TDP case, we observed TMEM106B expression extending into neuronal processes even in otherwise healthy-appearing neurons. Staining sections with a second TMEM106B antibody demonstrated similar results (Figure 4). Furthermore, TDP-43 pathology did not differ significantly between GRN (+) FTLD-TDP and GRN (-) FTLD-TDP 


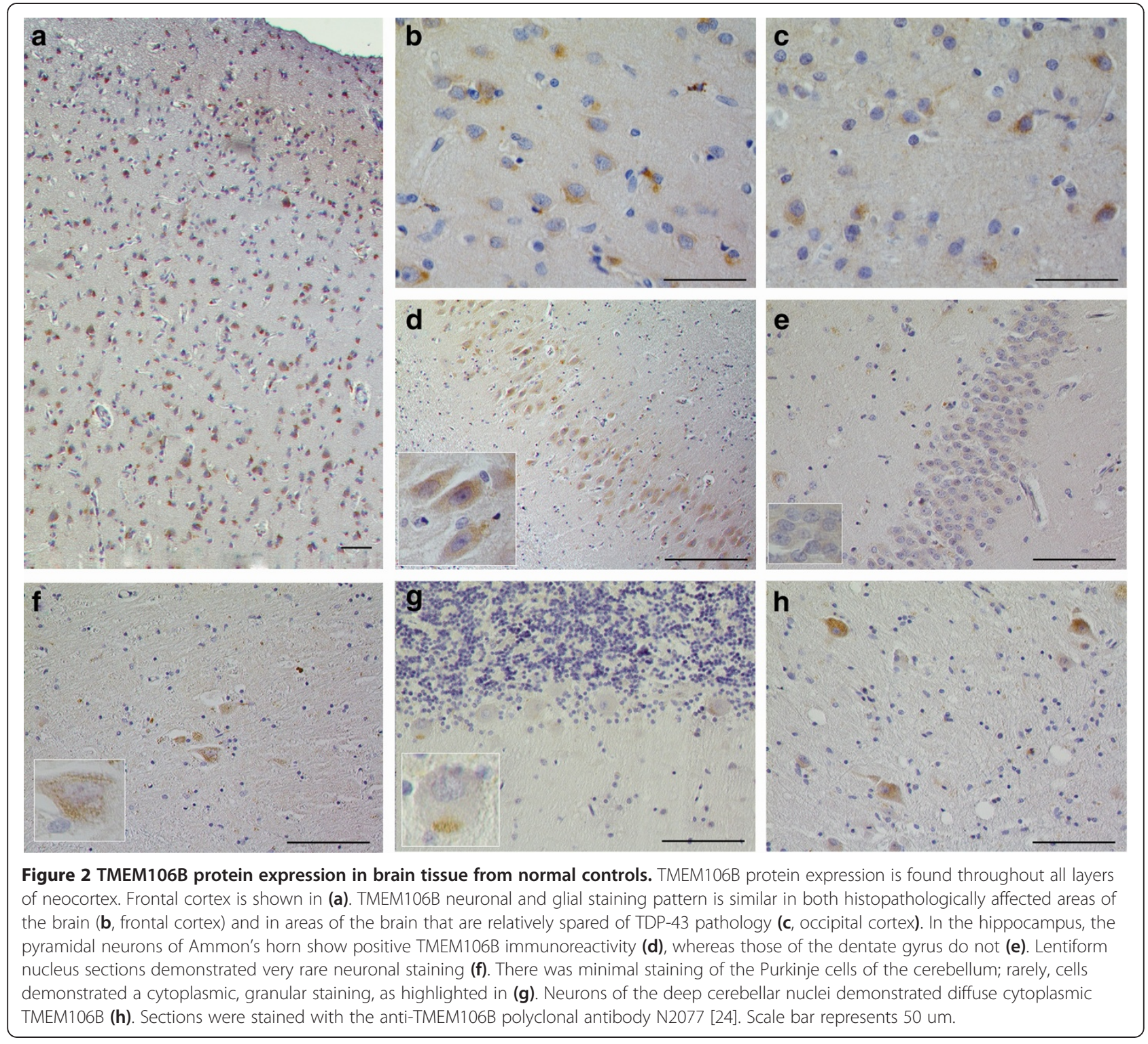

cases (Figure 4). Of note, GRN (-) FTLD-TDP cases used in this study were matched by histopathological subtype to GRN (+) FTLD-TDP cases; all were FTLDTDP Type A cases [31].

Thus, TMEM106B expression differs significantly in frontal cortex neurons of GRN (+) FTLD-TDP brain. Specifically, in this genetic subtype, TMEM106B is diffusely expressed throughout the neuronal cytoplasm, with frequent extension into neuronal processes.

\section{Discussion}

In this study, we have provided an initial characterization of TMEM106B protein expression in normal, GRN (-) FTLD-TDP, and GRN (+) FTLD-TDP human brain, as well as other neurodegenerative disease controls. We find that TMEM106B is normally expressed in the cytoplasm of neurons, glia, and peri-vascular endothelial cells or pericytes, although there may be differences based on neuronal subtype. Unlike many neurodegenerative disease-related proteins, TMEM106B does not form pathological inclusions in diseased brain. Instead, we show that neurons in GRN (+) FTLD-TDP cases exhibit more disorganized cytoplasmic TMEM106B expression than normal or disease controls. Specifically, TMEM106B expression in these cases demonstrates loss of polarity as well as subcellular compartmentalization.

In immortalized cell lines and primary cortical neurons, we and others have shown that TMEM106B is localized to endosomes or lysosomes [20,22-24]. We note that the pattern of TMEM106B staining in normal human brain tissue is compatible with this subcellular localization as well, although further studies using 

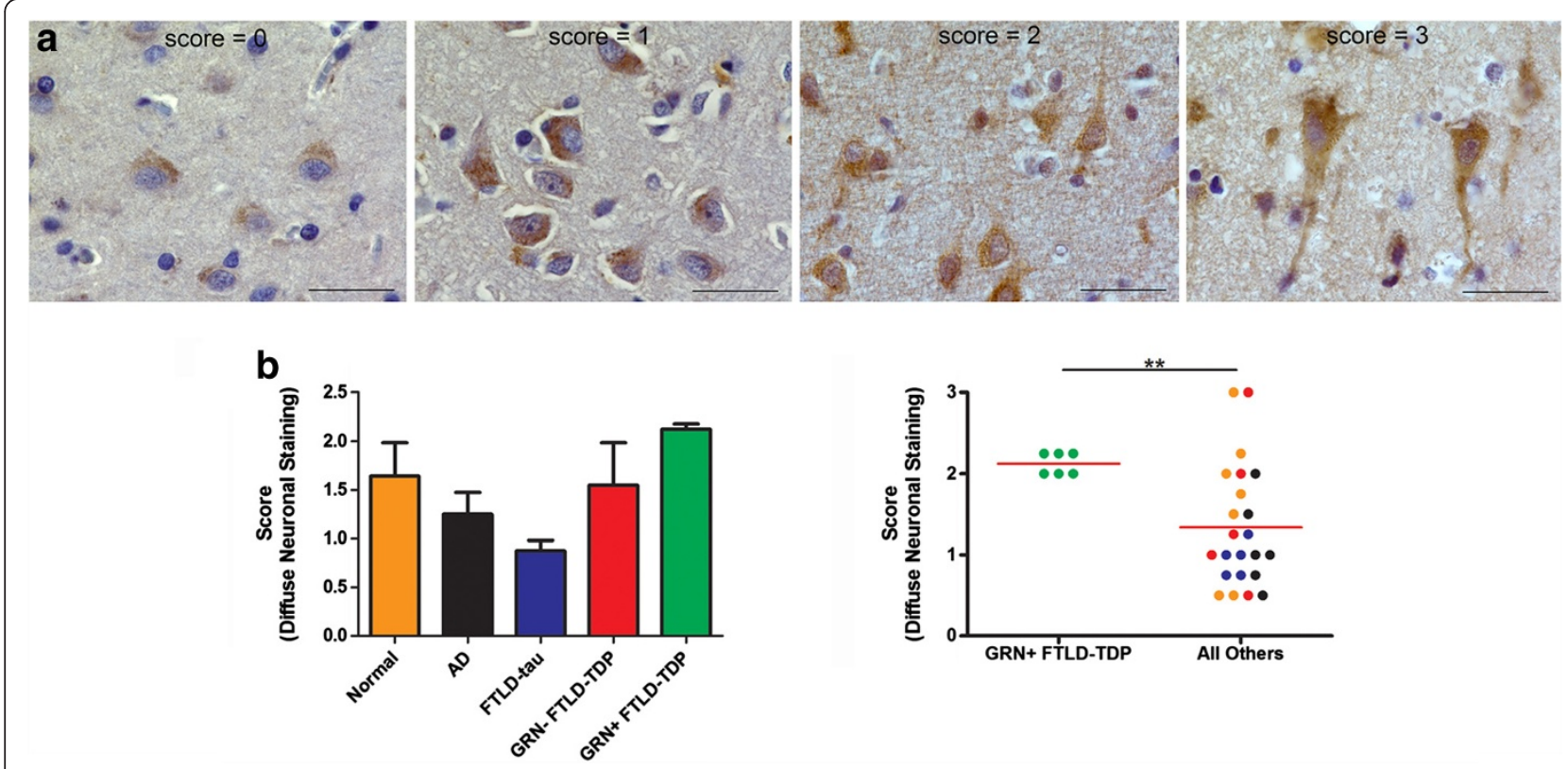

Figure 3 Scoring of neuronal TMEM106B protein expression. (a) Scoring schema used to grade severity of disorganization of neuronal TMEM106B expression. Scores of 0 were assigned to sections in which almost all neurons displayed cytoplasmic TMEM106B expression with a vesicular pattern exhibiting a polarized quality. Nuclear boundaries were clear. Scores of 1 were assigned to sections in which a sizeable number of neurons displayed more diffuse TMEM106B staining dispersed more widely in the cytoplasm, but still delimited to the soma. Polarity was still usually maintained. Scores of 2 were assigned to sections in which most neurons recapitulated the characteristics of a score of 1 . However, these sections also contained rare, non-degenerating neurons which displayed highly disorganized and diffuse TMEM106B staining throughout the cytoplasm with extension into processes. Scores of 3 were assigned to sections in which numerous neurons displayed highly disorganized and diffuse TMEM106B staining, with extension into processes. Scale bar represents $30 \mathrm{um}$. (b) Shown is the average scoring of the degree of diffuse neuronal TMEM106B expression by two independent, blinded scorers for N2077-stained human frontal cortical samples. Normal cases $n=7$; Alzheimer's disease $n=5$; FTLD-tau $n=6$, GRN (-) FTLD-TDP $n=5$, GRN (+) FTLD-TDP $n=6$. The colors in the dot plot correspond to the groups delineated in the bar graph. Weighted kappa $=0.44$. GRN (+) FTLD-TDP cases demonstrated more disorganized patterns of TMEM106B expression $(p=0.005$ for Mann-Whitney test).

double-label immunofluorescence would be needed to definitively demonstrate this.

The present finding that GRN (+) FTLD-TDP cases exhibit significantly different patterns of TMEM106B expression is intriguing. It is unlikely that this finding is due to neurodegeneration alone, since disease controls (FTLDtau, AD) showed the least disorganization. Moreover, GRN (-) FTLD-TDP cases with similar patterns of TDP43 pathology did not demonstrate TMEM106B expression extending into neuronal processes, suggesting that this effect is specific to the GRN (+) FTLD-TDP genetic subtype. We have previously shown that GRN (+) FTLD-TDP has a distinct global mRNA expression profile [32], suggesting that distinct pathophysiological mechanisms may exist in this molecularly defined subgroup. Moreover, recent evidence implicates TMEM106B in GRN (+) FTLD-TDP pathways. Specifically, we have previously shown that TMEM106B may be expressed at higher levels in GRN (+) FTLD-TDP brain [24], which is consistent with the histopathological pattern described here of TMEM106B expression throughout the neuronal cytoplasm in these genetic cases. Secondly, TMEM106B may act as a genetic modifier among GRN mutation carriers, influencing age at disease onset and levels of circulating progranulin $[26,27]$. Finally, we and others have recently demonstrated that over-expression of TMEM106B affects endo-lysosomal appearance and function as well as the distribution of progranulin in intracellular and extracellular compartments $[20,23,24]$.

In this context, the current study provides further evidence of a relationship between TMEM106B and progranulin, although the directionality of this relationship is unclear. The observation that GRN mutation carriers exhibit disordered TMEM106B expression suggests that abnormalities in progranulin can influence TMEM106B expression patterns, whereas the TMEM106B overexpression studies suggest that TMEM106B levels affect progranulin. One possibility to reconcile these findings is that a feedback loop exists between TMEM106B and progranulin in the pathogenesis of FTLD-TDP. Additional studies to investigate this possibility would be a valuable addition to the data presented here.

Our current study has several limitations. First, our sample size of 29 cases may not adequately represent the 


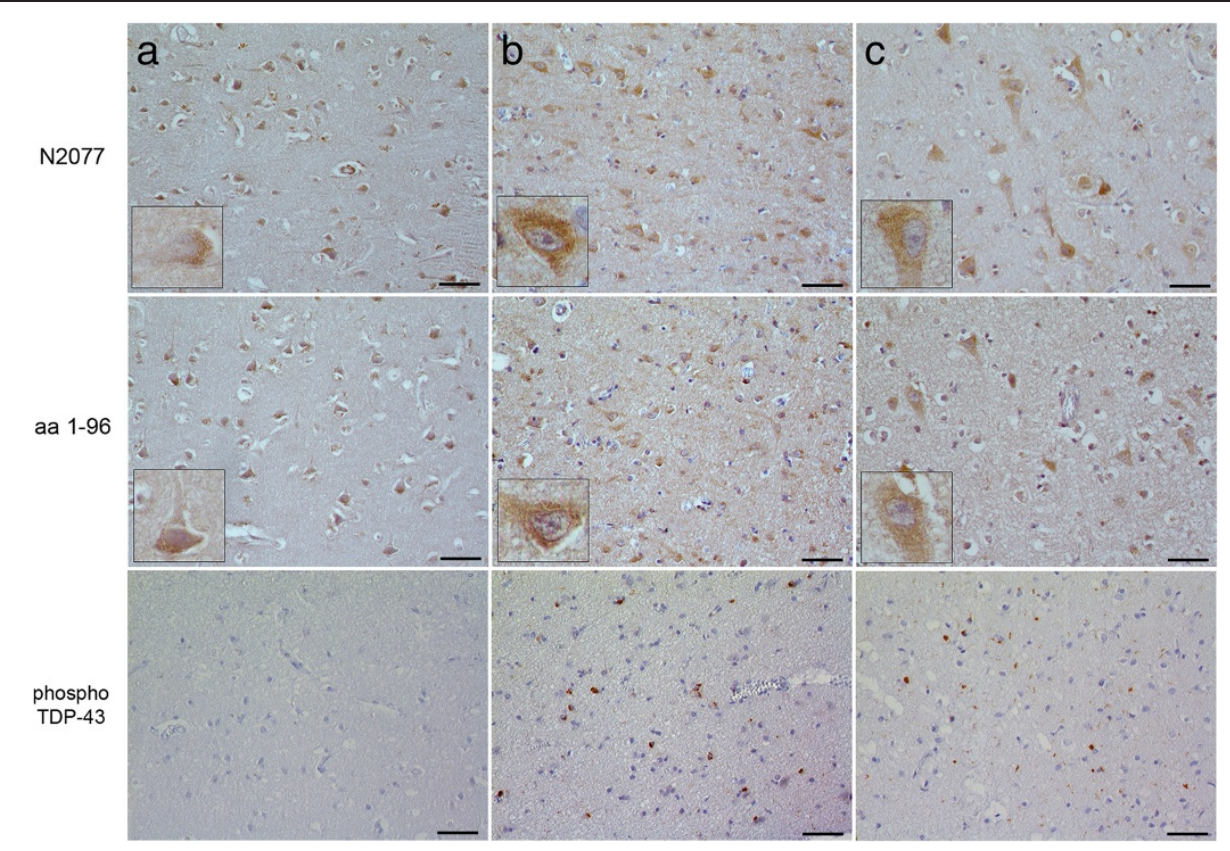

Figure 4 TMEM106B expression is more disorganized in neurons from GRN (+) FTLD-TDP cases, despite comparable levels of TDP-43 pathology. Representative frontal cortical sections from a normal control (a), GRN (-) FTLD-TDP (b), and GRN (+) FTLD-TDP (c). Both the N2077 antibody (top row) [24] and a different polyclonal antibody (middle row) raised against the N-terminus (amino acids 1-96) of TMEM106B [23] show similar patterns of immunoreactivity on serial sections from the same cases. GRN (+) FTLD-TDP cases showed more disorganized TMEM106B expression than GRN (-) FTLD-TDP cases, despite similar degrees of TDP-43 pathology, as indicated by staining against pathological, phosphorylated forms of TDP-43 (bottom row). Scale bar represents 50 um.

full range of TMEM106B expression that might exist in a larger sample size. However, even with this small sample size, we were able to detect a significant difference in TMEM106B expression in GRN (+) FTLD-TDP. Second, the use of postmortem brain samples limits our ability to interpret the current finding, since non-specific effects due to postmortem interval, disease duration, cell loss and gliosis could confound our results. Finally, samples used here were not strictly age- and gender-matched among groups. However, the GRN (+) FTLD-TDP group did not differ significantly from the other groups in these respects $(t$-test $\mathrm{p}=0.612$ for age comparison, chisquare $\mathrm{p}=0.775$ for sex comparison), decreasing the possibility that these demographic variables may account for the observed effect.

\section{Conclusions}

In conclusion, we have provided the first histological characterization of TMEM106B expression in multiple regions of pathological and normal human brain. Our data add to the growing body of evidence that TMEM106B and progranulin may be linked mechanistically in the pathogenesis of FTLD-TDP. Further characterization of this new FTLD-TDP risk factor, as well as its interactions with progranulin, may open up new avenues for the development of disease-modifying therapies.

\section{Methods}

\section{Brain samples}

Human postmortem brain samples were obtained from the University of Pennsylvania Center for Neurodegenerative Disease Brain Bank under IRB approval. These comprised samples from normal individuals $(\mathrm{n}=7)$, as well as individuals with FTLD-TDP $(\mathrm{n}=11)$, FTLD-tau $(n=6)$, and Alzheimer's disease $(A D, n=5)$. Regions sampled included midfrontal cortex, occipital cortex, cerebellum, lentiform nucleus, and hippocampus. See Additional file 1: Table S1 for a detailed list of cases. Histopathological subtyping for FTLD-TDP was performed according to established criteria [31]. Genetic testing for C9orf72 expansions, GRN mutations, and $M A P T$ mutations was performed as previously described $[33,34]$. One FTLD-TDP case was found to harbor a C9orf72 expansion -- TMEM106B expression in this case did not appear atypical for the GRN (-) FTLD-TDP group. In addition, 6 FTLD-TDP cases had GRN mutations, and no cases had MAPT mutations.

\section{Immunohistochemistry}

Formalin-fixed, paraffin-embedded $6 \mu \mathrm{m}$ sections from various brain regions were cleared in a descending ethanol series then blocked with $3 \% \mathrm{H} 2 \mathrm{O} 2 / \mathrm{MeOH}$ for 30 minutes. After washing, sections were immersed in Antigen Unmasking Solution (Vectashield) and microwaved 
$1 \times 10$ minutes at $50 \%$ power, then $2 \times 6$ minutes at $50 \%$ power. Slides were allowed to cool to room temperature, then washed with $0.1 \mathrm{M}$ Tris buffer, $\mathrm{pH} 7.6$ (Tris) for five minutes. Sections were blocked in Tris $+2 \%$ FBS, $\mathrm{pH} 7.6$ (Tris/FBS) for five minutes, before overnight incubation at $4^{\circ} \mathrm{C}$ with primary antibody (see Additional file 1: Table $\mathrm{S} 2$ for antibody conditions). Specimens were immersed in Tris buffer x 5 minutes, followed by Tris/ FBS x 5 minutes. Biotinylated goat anti-rabbit secondary antibody (Vectashield) was applied, and samples were incubated at room temperature in a humidified chamber for one hour. Samples were washed briefly in Tris. VECTASTAIN AB solution (Vector Labs) made up in Tris/FBS was applied to the samples and incubated for one hour at room temperature. Slides were then incubated with ImmPACT DAB solution (Vector Labs) for 2-8 minutes until desired stain intensity was achieved. Specimens were rinsed briefly with Tris, followed by $\mathrm{dH} 2 \mathrm{O}$ and then counterstained with Harris' hematoxylin (Thermo-Shandon) for 10-30 seconds. Slides were washed in running tap water for 5 minutes. Coverslips were sealed with Cytoseal (Thermo Scientific) and slides were allowed to dry for at least one hour.

TMEM106B antibodies used in this manuscript were N2077, a previously validated [24] polyclonal rabbit antibody directed at amino acids 4-19 of TMEM106B (a peptide sequence specific to TMEM106B). Additional data supporting the specificity of N2077 for TMEM106B are provided in Additional file 1: Figure S1. A second polyclonal rabbit antibody raised against amino acids 1-96 of TMEM106B was used to verify results; this second antibody has been previously validated as well [23].

\section{Semi-quantitative assessment of TMEM106B expression}

Two independent, blinded observers (MML and ACP) scored stained specimens from normal controls $(n=7)$, as well as from patients with Alzheimer's disease $(\mathrm{n}=5)$, FTLD-tau $(\mathrm{n}=6), G R N(+)$ FTLD-TDP $(\mathrm{n}=6)$, and GRN $(-)$ FTLD-TDP $(n=5)$, assessing for the nature and degree of neuronal staining. Specimens were assigned scores of $0-3$ based on an ordinal scale representing increasing loss of subcellular localization and polarity. Representative images and scoring criteria are described in the Results section.

\section{Additional file}

Additional file 1: Table S1. Characteristics of cases and brain regions evaluated for TMEM106B expression. Table S2. Antibodies and conditions used for immunohistochemical staining. Figure S1. Validation of TMEM106B antibody.

\section{Authors' contributions}

JB performed experiments, intepreted the data, and drafted the manuscript. EA performed experiments and revised the manuscript for experimental content. ML analyzed data and revised the manuscript for neuropathological content. MG recruited study participants and revised the manuscript for clinical content. WD performed genetic screening and revised the manuscript for genetic content. FH developed reagents and revised the manuscript for experimental content. VL and JQT banked and provided neuropathological specimens and edited the manuscript for neuropathological content. ACP conceived of and supervised the study, analyzed data, and drafted the manuscript. All authors read and approved the final manuscript.

\section{Acknowledgements}

We thank the many patients who contributed samples for this study. We thank Terry Schuck for technical assistance. This work was supported by the National Institutes of Health (NIH) (AG033101, AG00255), as well as a Burroughs Wellcome Fund Career Award for Medical Scientists and the Benaroya Fund (to ACP). VMYL is the John H. Ware, 3rd, Professor of Alzheimer's Disease Research. JQT is the William Maul Measey-Truman G. Schnabel, Jr., Professor of Geriatric Medicine and Gerontology.

\section{Author details}

${ }^{1}$ Departments of Neurology, Perelman School of Medicine at the University of Pennsylvania, Philadelphia, PA, USA. ${ }^{2}$ Departments of Pathology and Laboratory Medicine, Perelman School of Medicine at the University of Pennsylvania, Philadelphia, PA, USA. ${ }^{3}$ Department of Molecular Biology and Genetics, Cornell University, Ithaca, NY, USA. ${ }^{4}$ Department of Neurology, Perelman School of Medicine, 3610 Hamilton Walk, 166 Johnson Pavilion, Philadelphia, PA 19104, USA. ${ }^{5}$ Pathology and Laboratory Medicine, The Hospital of the University of Pennsylvania, 3400 Spruce Street, 6 Founders, Philadelphia, PA 19104, USA. ${ }^{6}$ Department of Neurology, The Hospital of the University of Pennsylvania, 3400 Spruce Street, 2 Gibson, Philadelphia, PA 19104, USA. PPathology and Laboratory Medicine, Perelman School of Medicine at the University of Pennsylvania, 3400 Spruce Street, 7.103 Founders Pavilion, Philadelphia, PA 19104, USA. ${ }^{8}$ Department of Molecular Biology and Genetics, Weill Institute for Cell and Molecular Biology, Cornell University, 345 Weill Hall, Ithaca, USA. ${ }^{9}$ University of Pennsylvania, 3600 Spruce Street, 3rd Floor Maloney Building, Philadelphia, PA 19104, USA.

Received: 4 July 2013 Accepted: 4 July 2013

Published: 11 July 2013

\section{References}

1. Neary D, Snowden J, Mann D: Frontotemporal dementia. Lancet Neurol 2005, 4:771-780

2. Ratnavalli E, Brayne C, Dawson K, Hodges JR: The prevalence of frontotemporal dementia. Neurology 2002, 58:1615-1621.

3. Cairns NJ, Neumann M, Bigio EH, Holm IE, Troost D, Hatanpaa KJ, Foong C, White CL 3rd, Schneider JA, Kretzschmar HA, Carter D, Taylor-Reinwald L, Paulsmeyer K, Strider J, Gitcho M, Goate AM, Morris JC, Mishra M, Kwong LK, Stieber A, Xu Y, Forman MS, Trojanowski JQ, Lee VM, Mackenzie IR: TDP-43 in familial and sporadic frontotemporal lobar degeneration with ubiquitin inclusions. Am J Pathol 2007, 171:227-240.

4. Chen-Plotkin AS, Lee VM, Trojanowski JQ: TAR DNA-binding protein 43 in neurodegenerative disease. Nat Rev Neurol 2010, 6:211-220.

5. McKhann GM, Albert MS, Grossman M, Miller B, Dickson D, Trojanowski JQ Work Group on Frontotemporal Dementia and Pick's Disease: Clinical and pathological diagnosis of frontotemporal dementia: report of the Work Group on Frontotemporal Dementia and Pick's Disease. Arch Neurol 2001, 58:1803-1809.

6. Mackenzie IR, Rademakers R, Neumann M: TDP-43 and FUS in amyotrophic lateral sclerosis and frontotemporal dementia. Lancet Neurol 2010, 9:995-1007.

7. Neumann M, Sampathu DM, Kwong LK, Truax AC, Micsenyi MC, Chou TT, Bruce J, Schuck T, Grossman M, Clark CM, McCluskey LF, Miller BL, Masliah E, Mackenzie IR, Feldman H, Feiden W, Kretzschmar HA, Trojanowski JQ, Lee VM: Ubiquitinated TDP-43 in frontotemporal lobar degeneration and amyotrophic lateral sclerosis. Science 2006, 314:130-133.

8. Arai T, Hasegawa M, Akiyama H, lkeda K, Nonaka T, Mori H, Mann D, Tsuchiya K, Yoshida M, Hashizume Y, Oda T: TDP-43 is a component of 
ubiquitin-positive tau-negative inclusions in frontotemporal lobar degeneration and amyotrophic lateral sclerosis. Biochem Biophys Res Commun 2006, 351:602-611.

9. Baborie A, Griffiths TD, Jaros E, McKeith IG, Burn DJ, Richardson A, Ferrari R, Moreno J, Momeni P, Duplessis D, Pal P, Rollinson S, Pickering-Brown S, Thompson JC, Neary D, Snowden JS, Perry R, Mann DM: Pathological correlates of frontotemporal lobar degeneration in the elderly. Acta Neuropathol 2011, 121:365-371.

10. Van Damme $P$, Van Hoecke A, Lambrechts D, Vanacker $P$, Bogaert E, van Swieten J, Carmeliet P, Van Den Bosch L, Robberecht W: Progranulin functions as a neurotrophic factor to regulate neurite outgrowth and enhance neuronal survival. J Cell Bio/ 2008, 181:37-41.

11. Gao X, Joselin AP, Wang L, Kar A, Ray P, Bateman A, Goate AM, Wu JY: Progranulin promotes neurite outgrowth and neuronal differentiation by regulating GSK-3beta. Protein Cell 2010, 1:552-562.

12. Gass J, Cannon A, Mackenzie IR, Boeve B, Baker M, Adamson J, Crook R, Melquist S, Kuntz K, Petersen R, Josephs K, Pickering-Brown SM, Graff-Radford N, Uitti R, Dickson D, Wszolek Z, Gonzalez J, Beach TG, Bigio E, Johnson N, Weintraub S, Mesulam M, White CL 3rd, Woodruff B, Caselli R, Hsiung GY, Feldman H, Knopman D, Hutton M, Rademakers R: Mutations in progranulin are a major cause of ubiquitin-positive frontotemporal lobar degeneration. Hum Mol Genet 2006, 15:2988-3001.

13. Baker M, Mackenzie IR, Pickering-Brown SM, Gass J, Rademakers R, Lindholm C, Snowden J, Adamson J, Sadovnick AD, Rollinson S, Cannon A, Dwosh E, Neary D, Melquist S, Richardson A, Dickson D, Berger Z, Eriksen J, Robinson T, Zehr C, Dickey CA, Crook R, McGowan E, Mann D, Boeve B, Feldman H, Hutton M: Mutations in progranulin cause tau-negative frontotemporal dementia linked to chromosome 17. Nature 2006, 442:916-919.

14. Cruts M, Gijselinck I, van der Zee J, Engelborghs S, Wils H, Pirici D, Rademakers R, Vandenberghe R, Dermaut B, Martin JJ, van Duijn C, Peeters K, Sciot R, Santens P, De Pooter T, Mattheijssens M, Van den Broeck M, Cuijt I, Vennekens K, De Deyn PP, Kumar-Singh S, Van Broeckhoven C: Null mutations in progranulin cause ubiquitin-positive frontotemporal dementia linked to chromosome 17q21. Nature 2006, 442:920-924.

15. Shankaran SS, Capell A, Hruscha AT, Fellerer K, Neumann M, Schmid B, Haass C: Missense mutations in the progranulin gene linked to frontotemporal lobar degeneration with ubiquitin-immunoreactive inclusions reduce progranulin production and secretion. J Biol Chem 2008, 283:1744-1753.

16. DeJesus-Hernandez M, Mackenzie IR, Boeve BF, Boxer AL, Baker M, Rutherford NJ, Nicholson AM, Finch NA, Flynn H, Adamson J, Kouri N, Wojtas A, Sengdy P, Hsiung GY, Karydas A, Seeley WW, Josephs KA, Coppola G, Geschwind DH, Wszolek ZK, Feldman H, Knopman DS, Petersen RC, Miller BL, Dickson DW, Boylan KB, Graff-Radford NR, Rademakers R: Expanded GGGGCC hexanucleotide repeat in noncoding region of C9orf72 causes chromosome 9p-linked FTD and ALS. Neuron 2011, 72:245-256.

17. Renton AE, Majounie E, Waite A, Simon-Sanchez J, Rollinson S, Gibbs JR, Schymick JC, Laaksovirta H, van Swieten JC, Myllykangas L, Kalimo H, Paetau A, Abramzon Y, Remes AM, Kaganovich A, Scholz SW, Duckworth J, Ding J, Harmer DW, Hernandez DG, Johnson JO, Mok K, Ryten M, Trabzuni D, Guerreiro RJ, Orrell RW, Neal J, Murray A, Pearson J, Jansen IE, et al: A hexanucleotide repeat expansion in C9orf72 is the cause of chromosome 9p21-linked ALS-FTD. Neuron 2011, 72:257-268.

18. Van Deerlin VM, Sleiman PM, Martinez-Lage M, Chen-Plotkin A, Wang LS, Graff-Radford NR, Dickson DW, Rademakers R, Boeve BF, Grossman M, Arnold SE, Mann DM, Pickering-Brown SM, Seelaar H, Heutink P, van Swieten JC, Murrell JR, Ghetti B, Spina S, Grafman J, Hodges J, Spillantini MG, Gilman S, Lieberman AP, Kaye JA, Woltjer RL, Bigio EH, Mesulam M, Al-Sarraj S, Troakes C, et al: Common variants at 7p21 are associated with frontotemporal lobar degeneration with TDP-43 inclusions. Nat Genet 2010, 42:234-239.

19. van der Zee J, Van Langenhove T, Kleinberger G, Sleegers K, Engelborghs $\mathrm{S}$, Vandenberghe R, Santens P, Van den Broeck M, Joris G, Brys J, Mattheijssens M, Peeters K, Cras P, De Deyn PP, Cruts M, Van Broeckhoven C: TMEM106B is associated with frontotemporal lobar degeneration in a clinically diagnosed patient cohort. Brain 2011, 134:808-815.

20. Nicholson AM, Finch NA, Wojtas A, Baker MC, Perkerson RB, Castanedes-Casey M, Rousseau L, Benussi L, Binetti G, Ghidoni R, Hsiung GY, Mackenzie IR, Finger E, Boeve BF, Ertekin-Taner N, Graff-Radford NR, Dickson DW, Rademakers R: TMEM106B p.T185S regulates TMEM106B protein levels: implications for frontotemporal dementia. J Neurochem 2013. epub before print.

21. Rollinson S, Mead S, Snowden J, Richardson A, Rohrer J, Halliwell N, Usher S, Neary D, Mann D, Hardy J, Pickering-Brown S: Frontotemporal lobar degeneration genome wide association study replication confirms a risk locus shared with amyotrophic lateral sclerosis. Neurobiol Aging 2011, 32:758. e1-7.

22. Lang CM, Fellerer K, Schwenk BM, Kuhn PH, Kremmer E, Edbauer D, Capell A, Haass C: Membrane orientation and subcellular localization of transmembrane protein 106B (TMEM106B), a major risk factor for frontotemporal lobar degeneration. J Biol Chem 2012, 287:19355-19365.

23. Brady OA, Zheng Y, Murphy K, Huang M, Hu F: The frontotemporal lobar degeneration risk factor, TMEM106B, regulates lysosomal morphology and function. Hum Mol Genet 2013, 22:685-695.

24. Chen-Plotkin AS, Unger TL, Gallagher MD, Bill E, Kwong LK, Volpicelli-Daley L, Busch Jl, Akle S, Grossman M, Van Deerlin V, Trojanowski JQ, Lee VM: TMEM106B, the risk gene for frontotemporal dementia, is regulated by the microRNA-132/212 cluster and affects progranulin pathways. J Neurosci 2012, 32:11213-11227.

25. Vass R, Ashbridge E, Geser F, Hu WT, Grossman M, Clay-Falcone D, Elman L, McCluskey L, Lee VM, Van Deerlin VM, Trojanowski JQ, Chen-Plotkin AS: Risk genotypes at TMEM106B are associated with cognitive impairment in amyotrophic lateral sclerosis. Acta Neuropathol 2011, 121:373-380.

26. Finch N, Carrasquillo MM, Baker M, Rutherford NJ, Coppola G, Dejesus-Hernandez M, Crook R, Hunter T, Ghidoni R, Benussi L, Crook J, Finger E, Hantanpaa KJ, Karydas AM, Sengdy P, Gonzalez J, Seeley WW, Johnson N, Beach TG, Mesulam M, Forloni G, Kertesz A, Knopman DS, Uitti R, White CL 3rd, Caselli R, Lippa C, Bigio EH, Wszolek ZK, Binetti G, et al: TMEM106B regulates progranulin levels and the penetrance of FTLD in GRN mutation carriers. Neurology 2011, 76:467-474.

27. Cruchaga C, Graff C, Chiang HH, Wang J, Hinrichs AL, Spiegel N, Bertelsen S, Mayo K, Norton JB, Morris JC, Goate A: Association of TMEM106B gene polymorphism with age at onset in granulin mutation carriers and plasma granulin protein levels. Arch Neurol 2011, 68:581-586.

28. Rutherford NJ, Carrasquillo MM, Li M, Bisceglio G, Menke J, Josephs KA, Parisi JE, Petersen RC, Graff-Radford NR, Younkin SG, Dickson DW, Rademakers R: TMEM106B risk variant is implicated in the pathologic presentation of Alzheimer disease. Neurology 2012, 79:717-718.

29. Dixon AL, Liang L, Moffatt MF, Chen W, Heath S, Wong KC, Taylor J, Burnett E, Gut I, Farrall M, Lathrop GM, Abecasis GR, Cookson WO: A genome-wide association study of global gene expression. Nat Genet 2007, 39:1202-1207.

30. Geser F, Martinez-Lage M, Robinson J, Uryu K, Neumann M, Brandmeir NJ, Xie SX, Kwong LK, Elman L, McCluskey L, Clark CM, Malunda J, Miller BL, Zimmerman EA, Qian J, Van Deerlin V, Grossman M, Lee VM, Trojanowski JQ: Clinical and pathological continuum of multisystem TDP-43 proteinopathies. Arch Neurol 2009, 66:180-189.

31. Mackenzie IR, Neumann M, Baborie A, Sampathu DM, Du Plessis D, Jaros E, Perry RH, Trojanowski JQ, Mann DM, Lee VM: A harmonized classification system for FTLD-TDP pathology. Acta Neuropathol 2011, 122:111-113.

32. Chen-Plotkin AS, Geser F, Plotkin JB, Clark CM, Kwong LK, Yuan W, Grossman M, Van Deerlin VM, Trojanowski JQ, Lee VM: Variations in the progranulin gene affect global gene expression in frontotemporal lobar degeneration. Hum Mol Genet 2008, 17:1349-1362.

33. Brettschneider J, Van Deerlin VM, Robinson JL, Kwong L, Lee EB, Ali YO, Safren N, Monteiro MJ, Toledo JB, Elman L, McCluskey L, Irwin DJ, Grossman M, Molina-Porcel L, Lee VM, Trojanowski JQ: Pattern of ubiquilin pathology in ALS and FTLD indicates presence of C9orf72 hexanucleotide expansion. Acta Neuropathol 2012, 123:825-839.

34. Van Deerlin VM, Gill LH, Farmer JM, Trojanowski JQ, Lee VM: Familial frontotemporal dementia: from gene discovery to clinical molecular diagnostics. Clin Chem 2003, 49:1717-1725.

doi:10.1186/2051-5960-1-36

Cite this article as: Busch et al:: Expression of TMEM106B, the frontotemporal lobar degeneration-associated protein, in normal and diseased human brain. Acta Neuropathologica Communications 2013 1:36. 